\title{
Dietary Protein Effects on Growth Performance, Carcass Traits and Expression of Selected Jejunal Peptide and Amino Acid Transporters in Broiler Chickens ${ }^{1}$
}

-Author(s)
Corzo A*,2
Loar II RE*
Kidd MT‡
Burgess SC†
* Department of Poultry Science, Mississippi
State University, MS 39762, USA.
₹ Department of Poultry Science, University
of Arkansas, Fayetteville, AR 72701, USA.
† Department of Basic Sciences, Mississippi
State University, MS 39762, USA.

\section{Mail Adress}

Alex Corzo

Box 9665

Mississippi State University, MS 39762

Tel: 662-325-1829

Fax: 662-325-8292

E-mail: acorzo@poultry.msstate.edu

\section{-Keywords}

Amino acid transporters, chicken, crude protein, PepT1, protein absorption.

1 This is Journal Article Number J11589 from the Mississippi Agricultural and Forestry Experiment Station supported by MIS-322220. Use of trade names in this publication does not imply endorsement by the Mississippi Agricultural and Forestry Experiment Station of the products, nor similar ones not mentioned.

2 To whom correspondence should be addressed: acorzo@poultry.msstate.edu

\section{EAcknowledgements}

The authors wish to express their gratitude to Drs. Paul Tillman and Rob Shirley with Ajinomoto Heartland LLC for the analyses of experimental ingredients and diets of this experimental project.

\begin{abstract}
The effect of dietary protein on growth, carcass traits and some specific intestinal intestinal peptide and amino acid transporters in broiler chickens was studied. Birds received a common pre-test diet, and were subsequently fed either a standard positive control diet (PC) or a reduced CP diet (RCP) from 21 to $42 \mathrm{~d}$ of age. Growth was negatively impacted with feeding of RCP as manifested by an increase in feed consumption and feed conversion ratio. Carcass traits also showed evidence of negative effects of feeding the RCP diet, leading to a reduction in carcass and breast meat yield and an increase in abdominal fat percentage. Blood plasma total protein was reduced when the broilers were fed the RCP diet. Expression of mRNA for one peptide (PepT1) and four AA intestinal transporters ( $b^{0,+} A T ;$ CAT2; $\mathrm{y}^{+} \mathrm{LAT2}$; EAAT3) was measured from the jejunum. Quantified mRNA for the AA transporters $\mathrm{y}^{+}$LAT2 and EAAT3 showed that they were upregulated in chickens fed the RCP-diet. The transport systems PepT1, $\mathrm{b}^{\mathrm{o}+} \mathrm{A} \mathrm{A}$, and CAT2, were not affected by the dietary treatment imposed.

The live and processing data validated the in vivo portion of the study and elucidated the negative impact of feeding the RCP diet, while the responses observed with the expression of the various transporters may help provide some insight on the physiological consequences and adaptations that birds endure when provided diets too low in CP for abnormally extended periods of time.
\end{abstract}

\section{INTRODUCTION}

The digestive processes that occur during gastric and intestinal digestion in the chicken have been well elucidated (Menzies \& Fisk, 1963; Zelikson et al., 1971; Scott et al., 1982). Denaturation of dietary proteins in feedstuffs is initiated prior to ingestion of proteinrelated foods, and occurs during the high temperatures to which feed ingredients are exposed during the feed manufacturing process (Briggs et al., 1999). In most countries feed is pelleted which exposes it to temperatures ranging from 80 to $90{ }^{\circ} \mathrm{C}$. As a result, tertiary and quaternary structures of protein present in animal and vegetable feed ingredients can be disrupted. This denaturation process is almost completed when food reaches the gastrointestinal tract of the bird where a multitude of enzymatic and acidic reactions cleave specific peptide linkages, and other related bonds associated with protein conformation. The result of this degradation process is the release of a number of individual amino acids (AA) and some short peptides.

Conversely, our understanding of AA and peptide transport across the intestinal epithelia of chickens is not well understood, and some of the transport systems and their regulation in the gastrointestinal tract of chickens (G. gallus domesticus) was only recently uncovered (Chen et 
al., 2005; Gilbert et al., 2008; Li et al., 2008). However, there is still a great need for better understanding of avian peptide and AA absorptive mechanisms, particularly during practical circumstances, of which the study herein investigates.

\section{MATERIALS AND METHODS}

\section{Chickens and diets}

Three hundred twelve d-old male broiler chicks (Ross $\times$ Ross 308 ) were obtained from a primary broiler breeder (Aviagen, 2005) hatchery and placed in twenty six floor pens $(0.9 \times 1.2 \mathrm{~m} / \mathrm{pen})$ after equalization of body weight across pens $( \pm 1.5 \mathrm{~g} /$ chick). Water and feed were supplied ad libitum. Lighting management consisted of $23 \mathrm{~h}$ light and $1 \mathrm{~h}$ of darkness. Temperature was set for the birds to achieve thermoneutrality throughout the study (Aviagen, 2005). All animal procedures were approved by the University's Institutional Animal Care and Use Committee.

Ingredients used in the experimental diets were analyzed for AA content by HPLC after acid hydrolysis (AOAC International, 2006). To prevent sulfur AA degradation during hydrolysis of the raw feed ingredients (prior to formulation of the diets) and the test diets, oxidation using performic acid was used to derive stable products of methionine and cysteine. The formed products, methionine sulphone and cysteic acid, were then determined by chromatography and calculated back to the methionine and cysteine content in the experimental diets in accordance with AOAC International (2006). Upon analyses, the nutrient matrix of the feed ingredients was updated and all the test diets were then formulated using linear programming that solved for energy, AA, mineral and vitamin needs that satisfied optimal growth. A common pre-test diet in crumble form, formulated to satisfy all nutrient recommendations (NRC, 1994) was fed from placement to $21 \mathrm{~d}$ of age (Table 1). Two test diets were then fed from 21 to $42 \mathrm{~d}$ of age in pellet form (Table 1), and were composed primarily of corn, soybean meal and pet-food-grade poultry meal (thirteen replicate pens per treatment). The diets were formulated to satisfy all nutrient recommendations for the 21 to $42 \mathrm{~d}$ period (NRC, 1994). The main difference between the diets was their CP value, which was calculated to have a 1.3 percentage point spread between the positive control diet (PC; $20.2 \% \mathrm{CP}$ ) and the reduced CP diet $(\mathrm{RCP} ; 18.9 \% \mathrm{CP})$. Although there was a difference in $\mathrm{CP}$ levels, this did not originate from a lack of any of the essential and critically limiting AA for poultry (NRC, 1994), but mostly due to a reduction of those nonessential AA. The calculated CP gap of 1.3 percentage points between treatments was possible without incurring a deficiency of other critically limiting AA for poultry due to Val and Ile supplementation via crystalline form to the RCP-diet. Furthermore, dietary Trp and Arg were calculated to be at adequate levels based on the contribution from soybean meal and poultry meal of the diet. Composite samples of both dietary treatments were obtained and analyzed for AA composition by HPLC after brief cold-acid wash as previously described by AOAC International (2006).

Table 1 - Composition of experimental diets (as-fed basis).

\begin{tabular}{|c|c|c|c|}
\hline \multirow[b]{2}{*}{ Ingredients (\% of diet) } & \multirow{2}{*}{$\begin{array}{c}\text { Common diet } \\
(0-21)\end{array}$} & \multicolumn{2}{|c|}{ Test diets (21-42 d) } \\
\hline & & $\begin{array}{l}\text { Positive } \\
\text { control }\end{array}$ & $\begin{array}{l}\text { Reduced } \\
\text { CP }\end{array}$ \\
\hline Corn & 56.536 & 66.847 & 66.533 \\
\hline Soybean meal & 34.836 & 25.023 & 22.260 \\
\hline Poultry by-product meal & 4.0 & 4.0 & 4.0 \\
\hline Poultry fat & 1.711 & 1.270 & 2.166 \\
\hline Dicalcium phosphate & 1.298 & 1.208 & 1.242 \\
\hline Calcium carbonate & 0.498 & 0.580 & 0.614 \\
\hline Sodium chloride & 0.461 & 0.466 & 0.469 \\
\hline Vitamin/mineral premix ${ }^{1}$ & 0.250 & 0.25 & 0.25 \\
\hline DL-Methionine & 0.265 & 0.185 & 0.221 \\
\hline L-Lysine-HCl & 0.094 & 0.121 & 0.220 \\
\hline Coccidiostat $^{2}$ & 0.05 & 0.05 & 0.05 \\
\hline L-Threonine & - & - & 0.049 \\
\hline Choline- $\mathrm{HCl}(60 \%)$ & - & - & 0.014 \\
\hline L-Valine & - & - & 0.012 \\
\hline L-Isoleucine & - & - & 0.001 \\
\hline \multicolumn{4}{|l|}{ Calculated composition $^{3}$} \\
\hline Crude protein & 23.6 & $20.2(20.3)$ & $18.9(19.2)$ \\
\hline AME, MJ/kg & 3,100 & 3,125 & 3,125 \\
\hline TSAA & 0.99 & $0.82(0.78)$ & $0.82(0.80)$ \\
\hline Lysine & 1.33 & $1.10(1.26)$ & $1.10(1.20)$ \\
\hline Threonine & 0.89 & $0.74(0.76)$ & $0.74(0.76)$ \\
\hline Calcium & 0.92 & 0.88 & 0.88 \\
\hline Available phosphorus & 0.46 & 0.44 & 0.44 \\
\hline Sodium & 0.22 & 0.22 & 0.22 \\
\hline Choline, mg/kg & 1,817 & 1,688 & 1,688 \\
\hline
\end{tabular}

1 - The vitamin and mineral premix contained per $\mathrm{kg}$ of diet: retinyl acetate, 2,654 $\mu \mathrm{g}$; cholecalciferol, $110 \mu \mathrm{g}$; dl--tocopherol acetate, 9.9 $\mathrm{mg}$; menadione, $0.9 \mathrm{mg}$; B12, $0.01 \mathrm{mg}$; folic acid, $0.6 \mu \mathrm{g}$; choline, 379 mg; d-pantothenic acid, 8.8 mg; riboflavin, 5.0 mg; niacin , 33 mg; thiamin, $1.0 \mathrm{mg}$; d-biotin, $0.1 \mathrm{mg}$; pyridoxine, $0.9 \mathrm{mg}$; ethoxiquin, $28 \mathrm{mg}$; manganese, $55 \mathrm{mg}$; zinc, $50 \mathrm{mg}$; iron, $28 \mathrm{mg}$; copper, $4 \mathrm{mg}$; iodine, 0.5 mg; selenium, $0.1 \mathrm{mg}$. 2 - Provided 60 grams of salinomycin $\mathrm{Na} / 907.2$ $\mathrm{kg}$ of diet to prevent intestinal coccidia from developing. 3 - Calculated and analyzed (in parenthesis) total amino acids

The mean bird weight of all pens was recorded at the initiation (21 d) and termination (42 d) of the experimental phase. Feed consumption and feed conversion was calculated at the end of the experiment. 
Mortality was recorded daily. At $42 \mathrm{~d}$ of age, 9 birds were randomly removed from each experimental unit (pen) and processed. Carcass and abdominal fat weights were obtained and recorded. Carcasses were chilled for $4 \mathrm{~h}$, followed by a manual dissecting and weighing of the breast Pectoralis major and minor muscles with bone and skin removed.

\section{Blood sample collection, preparation and analysis}

One bird was randomly selected from each pen at $42 \mathrm{~d}$ of age, and bled via intra-cardial puncture. Blood samples were collected into $3 \mathrm{~mL}$ heparanized tubes (Fisher HealthCare, Houston, TX) and centrifuged at $4000 \mathrm{rpm} \times \mathrm{g}$ for $10 \mathrm{~min}$. Blood plasma was then removed and stored at $-80{ }^{\circ} \mathrm{C}$ for later analysis. Subsequently, samples were analyzed for concentration of glucose, uric acid, total protein and albumin concentrations using an in vitro analyzer (Ektachem Model DT 60 autoanalyzer, Eastman Kodak Co., Rochester, NY, USA) according to procedures previously described (Elliot, 1984; Tietz, 1986). - Each test was performed by dispensing $10 \mu \mathrm{L}$ of plasma onto a new Kodak Ektachem slide. A specific slide was used for each type of test. The test was photometric and measured the change in absorbance that was proportional to the concentration. To ensure precision, the optics were tested and calibrated against known standards before and after each assay. Observed values in this study were in agreement with previously reported ones (Hrubec et al., 2002).

\section{Intestinal sample collection, preparation and analysis}

A bird from each pen was randomly selected at $42 \mathrm{~d}$ of age and euthanized by cervical dislocation. Following post-mortem, $1 \mathrm{~cm}^{3}$ from each bird's distal jejunum immediately prior to the Meckel's diverticulum was aseptically dissected and placed in TRI Reagent (Molecular Research Center, Inc., Cincinnati, OH, USA). Jejunum was selected because it is recognized as a major site for $A A$ and peptide uptake in chickens (Chen et al., 2005). Total RNA was extracted from the tissue from each sample according to the manufacturer's protocol. Total RNA was quantified with a NanoDrop spectrophotometer (NanoDrop Technologies, Inc., Wilmington, DE, USA) and all RNA samples were diluted to a concentration of $10 \mathrm{ng} / \mu \mathrm{L}$ using RNasefree water. RNA integrity was measured using a Bioanalyzer 2100 (Agilent) and the only samples with RNA integrity greater than 7.5 (derived from both the 28/18s ratio and amount of background) were used. A SYBR Green real-time reverse transcriptase PCR was used: SuperScript III Platinum SYBR Green One-Step System (Invitrogen Corp., Carlsbad, CA, USA), $10 \mu \mathrm{M}$ of each primer, an iCycler iQ Real-Time PCR Detection System [(Bio-Rad Laboratories, Inc., Hercules, CA, USA); $50{ }^{\circ} \mathrm{C}, 30 \mathrm{~min} ; 95^{\circ} \mathrm{C}, 5 \mathrm{~min} \times\left(95^{\circ} \mathrm{C}, 15 \mathrm{sec}\right.$; $\left.\left.60^{\circ} \mathrm{C}, 60 \mathrm{sec}\right)\right]$. Monitored transport systems were the peptide transporter PepT1 and the AA transporters $\mathrm{Na}^{+}$-independent cationic amino acid transporter 2 (CAT2), excitatory amino acid transporter 3 (EAAT3), $\mathrm{Na}^{+}$-independent cationic and $\mathrm{Na}^{+}$-dependent neutral amino acid transporter $2\left(\mathrm{y}^{+} \mathrm{LAT2}\right)$, and $\mathrm{Na}^{+}-$ independent cationic and zwiterionic amino acid transporter $\left(b^{o,+} A T\right)$. The primer sequences for these genes have been previously documented (Gilbert et al., 2007). All amplicons crossed intron-exon boundaries. Each real-time reverse transcriptase PCR was done in triplicate on 96-well plates and included no-template controls. The internal standard 285 was used as the house keeping gene, and all data were normalized to 28s (Kaiser et al., 2003). The PCR used 45 cycles and so for ease of interpretation all normalized mRNA values are expressed as 45 minus the CT value (i.e. so more mRNA is shown as a larger number).

\section{Statistical analyses}

Treatments were arranged in a randomized complete block design, where block corresponded to an area of the broiler research house. Data analysis was performed using the Statistical Analysis System's PROC MIXED program of SAS (2003). In the analysis for treatment effects, blocking was a random factor and a pen was used as the experimental unit for analysis.

\section{RESULTS}

Analysis of the experimental diets showed a close proximity between calculated versus analyzed values for dietary CP levels (Table 1). The calculated gap of 1.3 percentage points of $C P$ between the $P C$ and $R C P$ diets was in close proximity with the analyzed value, with an analyzed difference of 1.1 points of CP. The analysis of the first three limiting $A A$ in broiler chicken diets (total sulfur [Met+Cys], Lys, Thr), showed similar levels between treatments, and were close to what was calculated for total sulfur and Thr. Analyses of dietary Lys levels in the experimental diets were slightly higher and different between the treatments, but neither treatment approximated deficient levels (NRC, 
1994) and both were similar in concentration of the majority of amino acids thus no growth impairment was expected and later observed.

Birds raised from placement at $1 \mathrm{~d}$ of hatch and fed a common diet to $21 \mathrm{~d}$ of age arrived with satisfactory weights (826 $\pm 69 \mathrm{~g} / \mathrm{bird})$ prior to experimentation (Aviagen, 2005). The flock of birds showed overall good health and exhibited a small overall mortality for this $21-d$ period $(0.9 \%)$. Table 2 shows the results of the live performance and carcass yields of the broilers. It can be observed that both treatments resulted in similar ( $p>0.05)$ BW gain values, but it was obvious that this was as a consequence of the birds given the RCP-diet increasing $(p \leq 0.01)$ their feed consumption patterns. In turn, this resulted in a poorer $(p \leq 0.001)$ feed conversion value by the birds fed the RCP-diet when compared to those fed the PC-diet. Incidence of mortality was unaffected $(p>0.05)$ by the dietary treatments fed. After birds were processed, a decrease in carcass yield ( $p \leq 0.05)$ and breast meat yield ( $p \leq$ $0.05)$, and an increase $(p \leq 0.001)$ in the abdominal fat pad percentage was exhibited by birds that had been fed the RCP diet. These results are in agreement with those observed for live production.

Blood plasma analysespartially supports the responses observed during live production and carcass trait measurements (Table 3). Blood plasma total protein values were observed to be more than $8 \%$ higher $(p \leq 0.05)$ in those birds that had been fed the PC-diet when compared to those with the RCP-diet. Results for blood plasma albumin, glucose, or uric acid were not statistically significant $(p>0.05)$, but shared expected trends in support of observed live performance and carcass responses.

Quantification of mRNA for the peptide transporter PepT1 is displayed in Table 4. It was observed that feeding RCP-diets resulted in approximately a twofold increase in mRNA abundance for this particular transport system, but experimental variability variability may not have allowed for a statistically significant difference $(p=0.15)$. This trend of higher mRNA concentration was similar to the other monitored transport systems $b^{0,+} A T, C A T 2, y^{+} L A T 2$, and EAAT3 (Table 4). In the case of the AA transport system EAAT3 and $y^{+} L A T 2$, a higher $(p \leq 0.05)$ abundance of mRNA for the RCP-fed birds was statistically supported, while that of the systems CAT2 $(p=0.09)$ and $b^{o,+} A T(p=$ 0.11 ) was marginally supported.

Table 3 - Blood plasma albumin, total protein, glucose and uric acid of broilers fed diets that differed in crude protein level ${ }^{1}$.

\begin{tabular}{lcccc}
\hline Treatment & Albumin & Total protein & Glucose & Uric acid \\
\hline Positive control & 1.33 & $3.30 \mathrm{a}$ & 242.7 & 7.63 \\
Reduced CP & 1.22 & $3.03 \mathrm{~b}$ & 232.8 & 6.57 \\
Pooled SEM & 0.045 & 0.088 & 4.85 & 0.608 \\
P value & 0.12 & 0.042 & 0.16 & 0.23
\end{tabular}

$a-b$ - Means not sharing a common superscript within a column differ significantly $(p \leq 0.05) .1$ - Values for blood plasma albumin and total protein are levels expressed as $\mathrm{g} / \mathrm{dL}$; values for glucose and uric acid are expressed as $\mathrm{mg} / \mathrm{dL}$.

Table 4 - mRNA expression cycle threshold (Ct) of peptide transporter PepT1, and amino acids transporters $\mathrm{Na}^{+}$-independent cationic amino acid transporter 2 (CAT2), excitatory amino acid transporter 3 (EAAT3), $\mathrm{Na}^{+}$-independent cationic and $\mathrm{Na}^{+}-$ dependent neutral amino acid transporter 2 ( $\left.\mathrm{y}^{+} \mathrm{LAT} 2\right)$, and $\mathrm{Na}^{+}-$ independent cationic and zwiterionic amino acid transporter $\left(b^{0,+} A T\right)$, from jejunum of broilers fed diets that differed in crude protein level ${ }^{1}$.

\begin{tabular}{|c|c|c|c|c|c|}
\hline Treatment & PepT1 & CAT2 & EAAT3 & $y+$ LAT2 & $b^{0,+} A T$ \\
\hline Positive control & 21.62 & 16.24 & $21.08 \mathrm{~b}$ & $21.78 b$ & 25.80 \\
\hline Reduced CP & 22.87 & 17.06 & $21.80 a$ & $22.82 \mathrm{a}$ & 27.25 \\
\hline Pooled SEM & 0.62 & 0.39 & 0.31 & 0.39 & 0.59 \\
\hline$P$ value & 0.15 & 0.09 & 0.041 & 0.05 & 0.11 \\
\hline
\end{tabular}

a-b - Means not sharing a common superscript within a column differ significantly $(p \leq 0.05)$. 1 - Values are expressed as 40 minus $C t$. One Ct difference is equal to approximately a two-fold difference in mRNA content.

\section{DISCUSSION}

For years now, the poultry industry has been trying to reduce dietary CP which could ultimately represent significant monetary savings. For that purpose, studies

Table 2 - Live performance and carcase traits of broilers fed diets that differed in crude protein level.

\begin{tabular}{|c|c|c|c|c|c|c|c|}
\hline \multirow[b]{2}{*}{ Treatment } & \multicolumn{4}{|c|}{ Live performance } & \multicolumn{3}{|c|}{ Carcass traits ${ }^{1}$} \\
\hline & BW gain ${ }^{2}$ & Feed intake $^{3}$ & FCR4 & Mortality (\%) & Carcass & Abdominal fat & Breast meat \\
\hline Positive control & 2.05 & $3.62 \mathrm{~b}$ & $1.77 b$ & 1.92 & $68.0 \mathrm{a}$ & $1.35 b$ & $21.3 \mathrm{a}$ \\
\hline Reduced CP & 2.03 & $3.74 \mathrm{a}$ & $1.83 \mathrm{a}$ & 0.64 & $67.5 \mathrm{~b}$ & $1.57 \mathrm{a}$ & $20.8 b$ \\
\hline SEM & 0.022 & 0.037 & 0.009 & 0.825 & 0.13 & 0.038 & 0.13 \\
\hline$P$ value & 0.42 & 0.005 & 0.0002 & 0.53 & 0.013 & 0.0004 & 0.019 \\
\hline
\end{tabular}

$a-b$ - Means not sharing a common superscript within a column differ significantly $(p \leq 0.05)$. 1 - Carcase trait values correspond to the percentage weight (yield) of each trait relative to the full live weight. Values for carcass traits are the observed-means of pens each providing ca. 9 carcasses. Breast meat yield correspond to the weight of boneless skinless Pectoralis major and minor muscles. 2 - Values correspond to pen-mean body weight gain for the experimental period ( 21 to $42 \mathrm{~d}$ of age) expressed in $\mathrm{kg}$. 3-Values correspond to the feed consumption per bird for the experimental period ( 21 to $42 \mathrm{~d}$ of age) expressed in kg. 4 - Values correspond to the feed conversion values corrected for mortality weight of broilers for the experimental period ( 21 to $42 \mathrm{~d}$ of age). 
evaluating reduced dietary $C P$ levels for chickens have been well documented (Noblet et al., 1987; Moran et al., 1996; Kerr \& Kidd, 1999a; Kerr \& Kidd, 1999b). There is disagreement in the literature about the specific effects caused by an excessive reduction in dietary $C P$, but there seems to be a general agreement that there is a threshold point in poultry that if crossed, will ultimately lead to reduced growth. The practice of $C P$ reduction is not as sensitive with other production animals, as there are reports that dietary $\mathrm{CP}$ can be more successfully reduced in swine (Kerr, 2003; Kerr et al., 2003; Corzo et al., 2005). It is likely that the variability in the effects observed across studies in poultry is due to a multitude of factors but mostly due to the amount of dietary CP decreased and resultant balance of AA. The majority of reduced CP studies in broiler chickens have attempted to maintain a minimum requirement value for those essential $A A$ in broiler chickens, and therefore the reduction in dietary $C P$ has been generated at the expense of non-essential AA supply. The equal weight gain observed in the present study concomitant with an increase in feed consumption and feed conversion has been previously observed (Ferguson et al., 1998).

The validation of the effects of feeding RCPdiets to chickens was further corroborated with the observed decrease in carcass yield and breast meat yield, and the increase in abdominal fat percentage. The latter effect had been previously observed by other investigators when feeding reduced dietary CP diets to broiler chickens (Lipstein et al., 1975; Moran et al., 1992; Deschepper \& DeGroote, 1995; Moran et al., 1996; Bartov \& Plavnki, 1998). Furthermore, a previous study associated the increase in abdominal fat percentage with overall fat tissue deposition when feeding a reduced CP diet to broilers (Namroud et al., 2008). However, some of the previously mentioned investigators have disagreed when reporting breast meat yield responses as a consequence of dietary $C P$ reduction. For example, some investigators observed no effect of dietary CP levels on breast meat yield (Deschepper \& DeGroote, 1995; Namroud et al., 2008). Conversely, and in agreement with the present study, other investigators clearly showed an effect of dietary CP on breast meat tissue deposition and yield (Moran et al., 1992; Bartov \& Plavnki, 1998). Although each study may have merit and provide satisfactory explanations to their nutritional responses as a result of dietary CP status, the objective of the growth and carcass composition phase of this study was to substantiate a nutritional response observed in the chickens as a response of a high dietary $C P$ reduction while satisfying all critical limiting AA requirements. Furthermore, consumption of the diet containing approximately $18.9 \%$ of CP from 21 to $42 \mathrm{~d}$ may have also exacerbated the response observed considering it was for an extended period of time ( $21 \mathrm{~d})$, which is a feeding phase too extensive to be seen in the practice.

In light of the expected live performance and carcass trait responses to the dietary $\mathrm{CP}$ treatments fed, certain blood plasma variables were monitored in an effort to further support the physiological and metabolic differences being experienced by these two set of birds. However, total protein plasma concentration was the only variable that provided a significant insight into the changes being experienced by these birds. It is logical to propose that a lack of CP supply mostly from nonessential AA may lead to a shortage of these substrates in the blood plasma of chickens. Numerical decreases in blood plasma albumin, uric acid and glucose of chickens fed the RCP-diet displayed responses that agree with all other results, but failed to attain statistical significance. Perhaps a larger sample of birds from each experimental unit could have resulted in a less variable and more concrete statistical validation of these responses. In spite of this, the almost 9\% reduction in blood plasma total protein concentration coupled with the live performance and carcass yield responses observed, arguably provides sufficient evidence to validate the nutritional and metabolic challenge experienced by the birds that were fed the RCP-diet. For that purpose, we are confident that our in vivo model was accomplished, providing merit in the evaluation of selected $A A$ and peptide transport systems.

Expression of the different transport systems varied in their response, but once again, displayed a common trend. In the case of the peptide transporter PepT1, no differences were observed in the mRNA abundance of this absorptive mechanism $(P=0.15)$. It has been previously documented in humans that this transport system has the ability to adjust to certain AA imbalances or deficiencies (Adibi, 1997), and therefore the focus we gave this transport system. Gilbert et al. (2008) showed that chickens that varied in genetic line and fed a diet based of either soybean meal or corn gluten meal expressed PepT1 differently, while age of chickens was not a factor that influenced this transport system on its own. However, Gilbert et al. (2008) reported that age interacted with the two dietary regimens fed. In our study, in an effort to provide the birds in both treatments with an equal concentration 
of the limiting essential AA, the RCP-diet was fortified with L-Thr, L-Val and L-lle while the PC-diet was not. The approximately $6.2 \%$ of AA fed in free form would not have undergone gastric and enteric digestion, and more importantly would not have required the use of a peptide transporter such as PepT1, and may have contributed to the marginal response observed in the present study.

In mammals, there have been more than twenty individual AA transporters identified (Bröer, 2008). The majority of these transport systems have been recently recognized in the enterocytes of chickens (Chen et al., 2005; Gilbert et al., 2007; Gilbert et al., 2008; Li et al., 2008). Gilbert et al. (2008) identified the AA transport systems $b^{0,+} A T, C A T 2, y^{+} L A T 2$, and EAAT3 as those showing a differential expression in intestinal mRNA abundance in chickens in response to diet type. For that purpose, those four individual AA transporters were monitored in this study.

The AA transporter EAAT3 is known for its specificity towards the absorption of the acidic AA Glu and Asp. Because the reduction in CP with the RCP-diet was accomplished primarily at the expense of non-essential $A A$, this meant a reduction in the dietary concentrations of these two AA. As expected, analysis of the experimental diets showed that the PCtreatment contained $5.49 \%$ with Glu and Asp, while the RCP-diet contained $5.15 \%$. Despite the lower concentration of Glu and Asp when chickens were fed the RCP-diet, there seems to be an up-regulation of the EAAT3 system judging by the mRNA quantified for this transporter. This might indicate a physiological adaptation by these birds in an attempt to compensate for the reduction in Glu and Asp substrates with a highly expressed EAAT3 AA transporter. The AA transporter $\mathrm{y}^{+} \mathrm{LAT2}$ also showed responsiveness to the dietary treatments fed. This absorption system has shown to be $\mathrm{Na}^{+}$-independent for the uptake of basic AA (Lys, Arg, and His) and $\mathrm{Na}^{+}$-dependent for neutral AA absorption. Because of formulation and based on the fact that all basic AA are essential for poultry, the difference in the analyzed concentrations for the sum of these basic AA between the PC- and the RCP-diet was small (3.12 vs. 2.99\%, respectively). It is then likely that the up-regulation of this transport system may have occurred as a consequence of the higher concentration of neutral AA present in the PCdiet. On the other hand, neutral AA represent the vast majority of AA in dietary protein, fifteen in total, and non-essential $A A$ and essential are equally represented within. We propose that the up-regulation in the
Dietary Protein Effects on Growth Performance, Carcass Traits and Expression of Selected Jejunal Peptide and Amino Acid Transporters in Broiler Chickens

AA transporter $\mathrm{y}^{+} \mathrm{LAT2}$ may have occurred from the specific targeting of the dietary shortage of nonessential neutral AA in the RCP-diet.

The transport systems $b^{0,+} A T$ and CAT2 are for the most part specific for basic AA. The mRNA response by the AA transporters CAT2 and $b^{0,+} A T$ to the dietary treatments fed resulted in marginal effects $(p=0.09$ and $p=0.11$, respectively). The jejunal enterocytes seem to display a tendency to up-regulate these two transport systems in chickens that were fed RCP-diets. Perhaps the less significant response displayed by these two AA transporters compared to $\mathrm{y}^{+}$LAT2 2 and EAAT3 may be explained by substrate specificity of the experimental diets. However, the composite of all transporter systems evaluated herein suggests a similar pattern, and one that provides a rational explanation to the live performance and carcass traits observed herein.

An overview of the complied responses suggests that the increase in feed consumption exhibited by birds fed the RCP-diet could have been due to the slight differences between treatments, which theoretically were differences in non-essential AA. Analysis of the diets showed that there were very minor differences in Lys, TSAA, and Thr concentration, and corroborated the CP differences between the treatments therefore validating the experimental design. However, the adjustment of feed consumption exhibited by the RCP-fed birds resulted in these birds consuming more of the AA that were formulated to be similar between treatments as well as an increase in calorie consumption. This increase in calorie consumption can be appreciated by the increase in abdominal fat relative weight. Future research should consider a third treatment were birds are pair-fed to simulate the changes observed in feed consumption pattern.

In conclusion, there is suggestive evidence presented in this study that a reduction of certain dietary AA may not result in a down-regulation but an up-regulation of the AA transporters $\mathrm{y}^{+} \mathrm{LAT} 2$ and EAAT3, and possible to a lesser extent the AA transporters $\mathrm{b}^{0,+} \mathrm{AT}$ and CAT2, and the peptide transporter PepT1 in chicken jejunum. Judging by the mRNA responses, the lower dietary AA (mostly non-essential) resulted in an absorptive compensation of jejunal enterocytes, in an effort to support maintenance and growth activities of the broiler chickens in spite of a lack of specific substrates. However, in order to fully corroborate the metabolic and physiological changes observed and hypothesized in the present study, differential expression of the proteins per se is warranted, and future research should also include other sites in the small intestine. 


\section{REFERENCES}

Adibi SA. The oligopeptide transporter (Pept-1) in human intestine: Biology and function. Gastroenterology 1997; 113:332-340.

Association of Official Analytical Chemists International. Official methods of analysis. 18th ed. Arlington; 2006. Official Methods 985.28, 994.12, and 968.06.

Aviagen North America. Broiler management huide. Huntsville, AL; 2005.

Bartov I, Plavnik I. Moderate excess of dietary protein increases breast meat yield of broiler chicks. Poultry Science 1998; 77:680688.

Briggs JL, Maier DE, Watkins BA, Behnke KC. Effect of ingredients and processing parameters on pellet quality. Poultry Science 1999; 78:1464-1471.

Bröer S. Amino acid transport across mammalian intestinal and renal epithelia. Physiologial Reviews 2008; 88:249-286.

Chen $\mathrm{H}$, Pan $\mathrm{Y}$, Wong EA, Webb Jr. KE. Dietary protein level and stage of development affect expression of an intestinal peptide transporter (cPepT1) in chickens. Journal of Nutrition 2005; 135:193-198.

Corzo A, Fritts CA, Kidd MT, Kerr BJ. Response of broiler chicks to essential and non-essential amino acid supplementation of low crude protein diets. Animal Feed Science and Technology 2005; 118:319-327

Deschepper K, De Groote G. Effect of dietary protein, essential and non-essential amino acids on the performance and carcase composition of male broiler chickens. British Poultry Science 1995; 36:229-245.

Elliot RJ. Ektachem DT-60 analyzer. The Physician's. Leading Computer Journal 1984; 2:6.

Ferguson NS, Gates RS, Taraba JL, Cantor AH, Pescatore AJ, Ford MJ, Burnham DJ. The effect of dietary crude protein on growth, ammonia concentration, and litter composition in broilers. Poultry Science 1998; 77:1481-1487.

Gilbert ER, Li H, Emmerson DA, Webb Jr. KE, Wong EA. Developmental regulation of nutrient transporter and enzyme mRNA abundance in the small intestine of broilers. Poultry Science 2007; 86:1739-1753.

Gilbert ER, Li H, Emmerson DA, Webb Jr. KE, Wong EA. Dietary protein quality and feed restriction influence abundance of nutrient transporter mRNA in the small intestine of broiler chicks. Journal of Nutrition 2008; 138:262-271.

Hrubec TC, Whichard JM, Larsen CT, Pierson FW. Plasma versus serum: specific differences in biochemical analyte values. Journal of Avian Medicine and Surgery 2002; 16:101-105.

Kaiser P, Underwood G, Davison F. Differential cytokine responses following Marek's disease virus infection of chickens differing in resistance to Marek's disease. Journal of Virology 2003; 77:762768.

Kerr BJ, Kidd MT. Amino acid supplementation of low-protein broiler diets: 1. glutamic acid and indispensable amino acid supplementation. Journal of Applied Poultry Research 1999a; 8:298-309.

Kerr BJ, Kidd MT. Amino acid supplementation of low-protein broiler diets: 2. formulation on an ideal amino acid basis. Journal of Applied Poultry Research 1999b; 8:310-320.

Kerr BJ. Dietary manipulation to reduce environmental impact. Proceedings of the $9^{\text {th }}$ International Symposium on Digestive Physiology in Pigs; 2003; Alberta, Canada. p.139-158.

Kerr BJ, Southern LL, Bidner TD, Friesen KG, Easter RA. Influence of dietary protein level, amino acid supplementation, and dietary energy levels of growing-finishing pig performance and carcass composition. Journal of Animal Science 2003; 81:3075-3087.

Li H, Gilbert ER, Zhang Y, Crasta O, Emmerson D, Webb Jr. KE, Wong EA. Expression profiling of the solute carrier gene family in chicken intestine from the late embryonic to early post-hatch stages. Animal Genetics 2008; 39:407-424.

Lipstein B, Bornstein S, Bartov I. The replacement of some of the soybean meal by the first-limiting amino acids in practical broiler diets. 3. Effects of protein concentrations and amino acid supplementations in broiler finishing diets on fat deposition in the carcass. British Poultry Science 1975; 16:627-635.

Menzies G, Fisk A. Observations on the oxyntico-peptic cells in the proventricular mucosa of Gallus domesticus. Quarterly Journal of Microscopical Science 1963; 104:207-211.

Moran Jr ET, Bushong RD, Bilgili SF. Reducing dietary crude protein for broilers while satisfying amino acid requirements by least-cost formulation: Live performance, litter composition, and yield of fast food carcass cuts at six weeks. Poultry Science 1992; 71:16871694

Moran Jr ET, Stilborn HL. Effect of glutamic acid on broilers given submarginal crude protein with adequate essential amino acids using feeds high and low in potassium. Poultry Science 1996; 75:120-129.

Namroud NF, Shivazad M, Zaqhari M. Effects of fortifying low crude protein diet with crystalline amino acids on performance, blood ammonia level, and excreta characteristics of broiler chicks. Poultry Science 2008; 87:2250-2258.

National Research Council. Nutrient requirements of poultry. $9^{\text {th }}$ rev ed. Washington: National Academy Press; 1994.

Noblet J, Henry Y, Dubois S. Effect of amino acid balance on nutrient utilization and carcass composition of growing swine. Journal of Animal Science 1987; 65:717-726.

SAS Institute. SAS for windows: version 9.1.3. Cary; 2003.

Scott HM, Nesheim MC, Young RJ. Protein and amino acids. In: Nutrition of the chicken. 3rd ed. Ithaca: ML Scott \& Associates; 
Corzo A, Loar II RE, Kidd MT,

1982. p.58-118.

Tietz NW. Fundamentals of clinical chemistry. In: Clinical chemistry.

Philadelphia; WB Saunders; 1986. p.1-186.

Zelikson R, Eilam-Rubin G, Kulka RG. The chymotrypsinogens and procarboxypeptidases of chick pancreas. Journal of Biological Chemistry 1971; 246:6115-6120. 